\title{
The Effects of Abusive Supervision and Motivational Preference on Employees' Innovative Behavior
}

\author{
Jian Tian, Yan Peng * $*$ and Xing Zhou \\ School of Management, Xiamen University, No. 422 Siming South Road, Xiamen 361005, China; \\ 17820171150654@stu.xmu.edu.cn (J.T.); xzhou@xmu.edu.cn (X.Z.) \\ * Correspondence: 17820180155002@stu.xmu.edu.cn
}

Received: 30 July 2020; Accepted: 13 October 2020; Published: 15 October 2020

check for updates

\begin{abstract}
Individual innovative behavior has an important relationship with the sustainable development of an organization. Thus, mostly drawing on social cognitive theory, this study examined the relationship between abusive supervision and employees' innovative behavior, focusing on the mediating role of creative self-efficacy and the moderating role of motivational preference. In an analysis of time-lagged data from three technological, innovation-based enterprises in Shenzhen, this study found that abusive supervision was negatively related to employees' innovative behavior and that this relationship was mediated by creative self-efficacy. Moreover, motivational preference was found to moderate this relationship as well as that between abusive supervision and creative self-efficacy. Employees with higher levels of motivational preference (i.e., intrinsic motivational preference weighs more than extrinsic motivational preference) are more vulnerable to abusive supervision, causing lower creative self-efficacy performance and less innovative behavior. Alternately, employees with lower levels of motivational preference (i.e., extrinsic motivational preference weighs more than intrinsic motivational preference) are less vulnerable to abusive supervision, thus resulting in a weaker negative relationship between abusive supervision and their creative self-efficacy and innovative behavior.
\end{abstract}

Keywords: abusive supervision; creative self-efficacy; motivational preference; employees' innovative behavior

\section{Introduction}

Innovative behavior (e.g., the development, adoption, and implementation of new ideas in the workplace) has an important influence on the sustainable development of enterprises [1,2]. In other words, innovative behaviors are critical for organizational performance, success, and long-term survival [3,4]. Fortunately, ample research has been conducted in this domain [5,6]. Innovative behavior is a necessary factor within an enterprise if that enterprise wishes to establish a competitive advantage [7]. Such behaviors can help enterprises to survive and succeed in a rapidly changing and increasingly complex business environment [8]. What should be clarified is that, in comparison to creativity, employees' innovative behavior (EIB) encompasses a wider range, varying from small behaviors, such as making an improvement in a work routine, to implementing a theory or working out a new product $[4,9,10]$. In contrast, creativity just focuses on generating new ideas [11,12].

However, innovative behavior is a risky endeavor [2] that requires a great deal of effort from employees but provides no guarantee of satisfactory results. While engagement in innovative behavior can bring employees numerous benefits beyond the sense of intrinsic enjoyment it can bestow, failures in innovative behavior can incur losses for both the company and its employees $[2,10,11]$.

Therefore, EIB is affected not only by individual factors, but also by organizational factors such as leadership style $[1,13]$. Several kinds of leadership styles have been proven to have an impact on 
EIB such as constructive leadership [5], servant leadership [14], transformational leadership [15,16], transactional leadership [1], paternalistic leadership [17], ethical leadership [13,18], and inclusive leadership [19]. Most leadership styles have been found to have a positive influence on EIB. Therefore, it is valuable to explore the possible negative influence of unsustainable leadership styles (i.e., abusive supervision) on EIB. Reducing the negative impact of this form of supervision is critical for enterprise innovation in today's increasingly turbulent business environment. Abusive supervision is an unsustainable leadership behavior wherein a supervisor engages in the disrespect, open ridicule, and discouragement of employees [20,21], and it can negatively impact both employees' attitudes and their behavior [22]. Abusive supervision has been shown to negatively affect employees' job satisfaction and even their vocal behavior and organizational citizenship behavior [23-26]. In addition, it can lead to increased psychological distress and emotional exhaustion of employees, with consequences such as workplace deviation behavior and high turnover rates [22,27-30]. Although some studies have examined the impact of abusive supervision on EIB [31], only a few have been carried out in the Chinese context $[32,33]$. Thus, the first goal of this study is to verify the negative influence of abusive supervision on innovative behavior in the context of China.

Further, although existing studies have explored the antecedents of innovative behavior from the perspectives of social exchange theory [5], social cognitive theory (SCT) [32], conservation of resources theory [33], and leader-member exchange theory [2], the perspective of self-determination theory (SDT) has received little attention. SDT is a comprehensive theory about individuals' motivation and regulation, which is developed around individuals' basic psychological needs (i.e., autonomy, competence, and relatedness), as well as intrinsic and extrinsic motivations [34]. Therefore, we have incorporated it into our research along with SCT [35-37] to explore the underlying mechanisms of how abusive supervision influences EIB and what the boundary conditions may be. In considering the question of how, the study aims to verify the mediating role of employees' creative self-efficacy (CSE). That is, surroundings (i.e., abusive supervision) may influence individual behavior (i.e., EIB) through individual cognition (i.e., CSE) [35].

Finally, our research addresses the boundary condition by investigating the moderating role of employees' motivational preference in the relationships between abusive supervision and innovative behavior as well as CSE. Motivation is what can impel individuals to do something [34] and may be categorized into intrinsic motivation and extrinsic motivation [38]. The former arises from the intrinsic value of the work (i.e., enjoyment, interest, satisfaction of curiosity, or personal challenge in the work), while the latter arises from other results outside of work (i.e., incentives, deadlines, surveillance, or dictates) [39]. Motivational preference is a relatively stable personality trait that varies from person to person [38] and reflects an individual's preferences for or tendencies toward motivational factors and is relatively consistent across time and situations. Intrinsic motivational preference (IMP) and extrinsic motivational preference (EMP) could co-exist within an individual simultaneously [38,39]. Further, high motivational preference refers to a situation when IMP weighs more than EMP, while low motivational preference includes weightier EMP than IMP.

Due to the fact that abusive supervision is measured by employees' perceptions of supervisors' workplace abuses [28,40], individuals with different levels of motivational preference have different ideas about abusive supervision. According to their tendency to focus on work tasks and the satisfaction of intrinsic goals, employees with high motivational preference (i.e., more IMP) are highly affected when confronted with abusive supervision, causing the negative impact of abusive supervision on their CSE and innovative behavior to be more severe. Alternately, employees with low motivational preference (i.e., more EMP) tend to pay more attention to the persuasion of financial incentives or avoiding punishment, and thus, they are less affected by abusive supervision, which reduces the negative influence of abusive supervision on their CSE and innovative behavior.

Based on SDT [34] and SCT [35-37] and the above argument, our study proposes the following integrated framework to test the mediating role of employees' CSE, which underlies the relationship between abusive supervision and EIB. This framework has also been designed to test the moderating 
effect of motivational preference on the negative link between abusive supervision and employees' CSE as well as that between abusive supervision and innovative behavior. The theoretical model is shown in Figure 1.

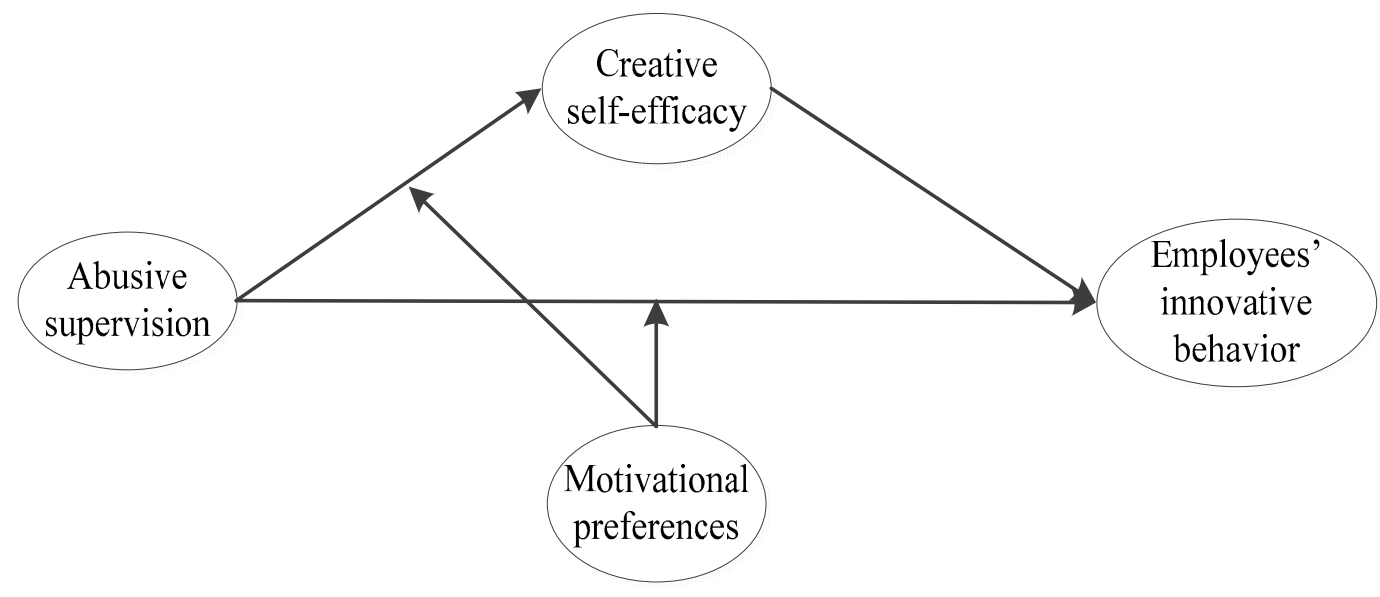

Figure 1. Research framework.

\section{Literature Review and Research Hypotheses}

\subsection{Abusive Supervision and Employees' Innovative Behavior}

Abusive supervision is a prevailing global phenomenon and one that has become increasingly frequent in the workplace [28,41]. It refers to employees' perceptions of supervisors being engaged in constant hostile verbal and nonverbal behavior, excluding physical contact $[28,40]$. Unlike punitive action, abusive supervision is a constant management style. Regardless of employees' performance, the supervisors' behavior is persistently destructive. Abusive supervision can lead to various negative consequences, including less organizational citizen behavior, poorer vocal behavior, and more counterproductive behavior $[25,26,42]$. The reduction of EIB is another adverse consequence of abusive supervision. Unlike creativity, which is just the production of novel and useful ideas [43,44], innovative behavior involves several stages including problem recognition, the generation of ideas or solutions, building support for ideas, and idea implementation [1,45]. However, borrowing Amabile's [46] comprehensive psychology of creativity framework, which describes how various factors (including personality, cognition, as well as social environment) affect individual creativity, we believe that abusive supervision is an external factor that will have an impact on individuals' innovative behavior.

EIB is a significant workplace behavior that has effects upon the sustainable development of an organization [1]. According to SCT [35-37], this paper proposes that EIB can be negatively affected by abusive supervision in several ways. First, from a psychological perspective, as SCT argues, individual behavior affects and is also influenced by individual cognition and the surroundings [35-37,47,48]. EIB is a complex behavior with high uncertainty that requires a great deal of personal and team effort, as well as the support of the organization and supervisors. However, abusive supervision produces a certain degree of oppression in the workplace, reducing employees' opportunities to develop thinking activities [49]. In addition, abusive supervision creates a stressful working environment, which may suppress employees' new ideas and prevent them from enacting innovative behaviors. Under such circumstances, abused employees do not have sufficient energy to complete innovative activities. Second, no matter how well employees have performed an action, abusive supervision sends a negative message to employees, as abusive supervisors are disrespectful, openly ridiculing, and discouraging $[20,21]$. This conveys a negative reinforcement of employees' working behavior, including innovative behavior [35], further compelling them to doubt whether their organizations respect their contributions and whether their jobs are meaningful to their own and to the organization's 
development [42]. This can lead to a reduction in innovative behavior in response to abusive supervision. Thus, we propose the following hypothesis:

Hypothesis 1 (H1). Abusive supervision is negatively related to EIB.

\subsection{Mediating Effect of Creative Self-Efficacy}

CSE refers to individuals' belief in the achievements of innovative products and the application of creative methods in the working process [50]. It is one's self-assessment of their own creative potential. Individuals with high CSE believe that they possess the ability to complete a task creatively and successfully [51]. Both individual factors and various leadership styles can contribute to different levels of CSE $[43,52,53]$.

This paper draws upon SCT [35-37], arguing that CSE mediates the relationship between abusive supervision and EIB. SCT suggests that individuals' perceptions of CSE and expectations of outcomes vary depending on the situation [54]. Abusive supervision creates a negative organizational atmosphere, threatening personal growth and the sustainable development of the organization [55]. When employees are subjected to abusive supervision, they believe that their supervisors lack respect for them and do not want to be associated with them. Through observational learning, individuals' cognition of CSE could be affected by abusive supervision and thus decrease [35].

The reduced CSE further influences EIB. CSE is not only a complicated type of self-perception, but it also includes a belief in accordance with individuals' goals within the framework of SCT $[35,56]$. Previous research has shown that innovative activities often require high levels of self-efficacy $[57,58]$. CSE represents the extent to which individuals believe in their own innovation ability [51]. High CSE employees are more confident about their ability to carry out tasks requiring innovation ability and to mobilize and utilize cognitive resources [59]; that is, they engage more in innovative behavior [50,51,60,61]. However, when employees' CSE is low, meaning there is less CSE to stimulate the desire for innovative behavior and help them to overcome difficulties in creative ways [51], they put forth less effort and take fewer actions toward solving problems or meeting situational demands [62]. Since innovative behavior requires a large amount of effort and resources, employees with low CSE are involved in less innovative behavior.

Integrating the above deduction, abusive supervision could negatively influence EIB through their CSE. Thus, we propose the following hypothesis:

Hypothesis 2 (H2). Abusive supervision negatively influences CSE and further decreases EIB.

\subsection{Moderating Effect of Motivational Preference}

Abusive supervision is a subjective assessment of employees [32] and, therefore, its influence on EIB is affected by individual characteristics. Motivational preference is one such kind of personal trait that may play a moderating role in this relationship. An individual might have more IMP or EMP. Individuals with high IMP perform a task due to intrinsic motivation because the task itself is enjoyable and gratifying (i.e., intrinsic motivations) and doing so can meet their basic needs [63]. At the same time, individuals with high EMP are more likely to be affected by extrinsic motivation, out of which employees complete a task because they seek an outcome other than the activity itself, for example, obtaining a reward or avoiding punishment [49]. According to Amabile et al. [38,39], individuals could have both IMP and EMP of varying degrees at the same time. In this study, motivational preference is regarded as a construct describing whether an employee tends to have more IMP or EMP. More specifically, according to the extent of and corresponding to the level of one's IMP and EMP, one's overall motivational preference can be high or low.

Stable motivational preference is the basis for responses to specific environmental conditions [38] and can directly influence an individual's perception and understanding of leadership behavior as 
well as their own performance [64]. As such, different levels of motivational preference may moderate the negative relationship between abusive supervision and employees' CSE as well as that between abusive supervision and EIB.

From the perspective of SDT, autonomy, competence, and relatedness are the three basic psychological needs that should be continuously met in one's life $[34,65,66]$. Individuals with more IMP (i.e., a higher level of motivational preference) focus more on their inner desires, looking forward to the fulfillment of their internal goals and experiencing positive emotions by completing the task itself $[67,68]$. However, when faced with abusive supervision, they are more likely to regard it as a personal offense that conveys supervisors' doubts about employees' autonomy and competence. At the same time, the joy of innovative behavior itself is diminished by the chronic suppression of abusive supervision. It then negatively affects EIB. In contrast, individuals with more EMP (i.e., a lower level of motivational preference) are motivated to complete tasks due to external rewards or punishment avoidance [49]. Their innovative behaviors are often driven by rewards, such as financial incentives, rather than by leadership styles. Therefore, when external incentives are high enough, workers can effectively adjust their emotions and maintain high innovative behavior despite abusive supervision. Furthermore, it can be inferred that a lower motivational preference could alleviate the negative effect of abusive supervision on innovative behavior.

From the perspective of SCT, individuals tend to be self-directed; thus, higher and lower motivational preference individuals conduct themselves differently [35]. Employees keep themselves motivated by monitoring their behavior and by setting rewards. Individuals with a higher motivational preference treasure the achievement of inner goals; however, abusive supervision gives them negative feedback and makes them feel embarrassed and awkward [69]. Under these circumstances, employees reduce their innovative behavior since there is no valuable feedback. In contrast, when they care less about supervisors' abuses, individuals with lower motivational preference motivate themselves to innovate by achieving other external goals, such as monetary rewards. The negative effects of abusive supervision on the innovative behavior of high EMP individuals should then be mitigated. Thus, we propose the following hypothesis:

Hypothesis 3 (H3). Individuals' motivational preferences moderate the negative relationship between abusive supervision and EIB such that the negative relationship is stronger when employees have high rather than low levels of motivational preference.

In addition to moderating the relationship between abusive supervision and EIB, motivational preference may also moderate the link between abusive supervision and CSE. In accordance with SCT, the environment affects individual cognition [35]. Further, the differences in perception of external environment and events caused by the different levels in individual motivational preference affect cognition to variable degrees.

Faced with abusive supervision, individuals with higher motivational preference will feel that this type of supervision is a kind of attack on their autonomy, competence, and relatedness, and it blocks their pursuit of internal goals. In particular, while the need for competence refers to individuals' demands for accomplishing difficult and challenging tasks to achieve the desired results [70], it has something in common with CSE [50]. High motivational preference related to individuals' pursuit of inner goals (i.e., sense of competence coming from the joy of completing the job itself) could aggravate the negative effects of abusive supervision on CSE. However, individuals with lower motivational preference value other external consequences of their work. Their CSE would not be affected much because cognition of their own CSE is not based on leadership styles but on the positive feedback of extrinsic outcomes. Thus, we propose the following hypothesis:

Hypothesis 4 (H4). Individuals' motivational preferences moderate the negative relationship between abusive supervision and CSE such that the negative relationship is stronger when employees have a high rather than a low level of motivational preference. 
Aligned with the arguments outlined above, we propose an integrated model in which CSE serves as a mediator between abusive supervision and EIB. Moreover, the negative effects of abusive supervision on both CSE and EIB are stronger when employees have a high level of motivational preference rather than a low level of motivational preference. Specifically, for employees with a higher level of motivational preference, their CSE decreases more when facing abusive supervision, which further reduces EIB. Accordingly, we propose the following hypothesis:

Hypothesis 5 (H5). Individuals' motivational preferences moderate the indirect effect of abusive supervision on EIB through CSE, such that this indirect relationship is stronger for employees with high levels of motivational preference.

\section{Materials and Methods}

\subsection{Samples and Procedures}

The data used in this study were collected from three technological innovation-based enterprises in Shenzhen in September 2018. We used a three-wave time-lagged survey to reduce potential common method bias [71]. In the first stage (T1), 395 questionnaires were distributed to measure employees' perceptions of abusive supervision from their immediate supervisors and to collect their basic demographic information. A total of 294 questionnaires were received, yielding a response rate of $74.4 \%$. Two months later (T2), we sent a second wave of questionnaires to the employees to construct ratings of their motivational preference and CSE. A total of 227 completed questionnaires were collected, yielding a response rate of $77.2 \%$. For stage three, which occurred another two months later (T3), surveys were distributed among direct supervisors who rated their EIB. Finally, we received a total of 190 valid questionnaires, generating a response rate of $83.7 \%$. Of these 190 respondents, $48.4 \%$ were male and $83.2 \%$ were between 20 and 30 years old. Regarding education, $42.1 \%$ had a high school diploma or lower, while $54.7 \%$ held a junior college degree and $3.2 \%$ held a bachelor's degree or higher. Furthermore, $69.5 \%$ of the respondents had worked for their enterprises for more than 2 years.

\subsection{Measures}

Abusive supervision was measured using 15 items developed from Tepper [22]; an example item is "My supervisor ridicules me." The Cronbach's alpha for abusive supervision was 0.83. CSE was measured using eight items adopted from Carmeli and Schaubroeck [72]; an example item is "I believe that I can succeed at most any creative endeavor to which I set my mind." The Cronbach's alpha for CSE was 0.89. Motivational preference was measured using 12 items from Amabile et al. [39]. Six items were used to measure IMP; an example item is "I want my work to provide me with opportunities to increase my knowledge and skills." A further six items were used to measure EMP; an example item is "I want other people to see how good I really can be at my work." The Cronbach's alphas for IMP and EMP were 0.75 and 0.78 , respectively. We calculated the motivational preference score by subtracting the standardized EMP score from the standardized IMP score, such that a higher motivational preference score reflects more IMP, whereas a lower motivational preference score reflects more EMP. Scott and Bruce's [45] six-item EIB scale was also employed; an example item is "generates creative ideas." The Cronbach's alpha for EIB was 0.70. In addition, information on gender, educational qualifications, and organizational tenure was collected. To guarantee that all items were suitable and applicable to the Chinese context, we adhered to the conventional back-translation procedure [39]. Responses were measured on a five-point Likert scale $(1=$ strongly disagree to $5=$ strongly agree). 


\section{Results}

\subsection{Confirmatory Factor Analysis and Common Method Bias}

The confirmatory factor analysis results showed that the five-factor model (including abusive supervision, EIB, CSE, IMP, and EMP) offered an acceptable fit to the data $\left(\chi^{2}=869.247, \mathrm{CFI}=0.947\right.$, $\mathrm{TLI}=0.943$, and RMSEA $=0.026$ ). In addition, the discriminant validity of all five constructs was tested by contrasting the baseline model with other alternative models. The fit indices of Table 1 revealed that the baseline model fit the data considerably better than any of the alternative models, and thus, the discriminant validity of the five variables was confirmed.

Table 1. Comparison of fit of alternative models $(N=190)$.

\begin{tabular}{|c|c|c|c|c|c|c|}
\hline Model & $x^{2}$ & df & $\chi^{2} / \mathrm{df}$ & RMSEA & TLI & CFI \\
\hline One-Factor Model & 1780.844 & 779 & 2.286 & 0.082 & 0.441 & 0.469 \\
\hline $\begin{array}{l}\text { Four-Factor Model 1: } \\
\text { EMP and IMP combined into one factor }\end{array}$ & 1089.951 & 773 & 1.410 & 0.047 & 0.822 & 0.832 \\
\hline $\begin{array}{l}\text { Four-Factor Model 2: } \\
\text { EIB and CSE combined into one factor }\end{array}$ & 991.983 & 773 & 1.283 & 0.039 & 0.877 & 0.884 \\
\hline $\begin{array}{l}\text { Four-Factor Model 3: } \\
\text { AS and EIB combined into one factor }\end{array}$ & 965.822 & 773 & 1.249 & 0.036 & 0.892 & 0.898 \\
\hline $\begin{array}{l}\text { Four-Factor Model 4: } \\
\text { AS and CSE combined into one factor }\end{array}$ & 1268.959 & 773 & 1.642 & 0.058 & 0.721 & 0.737 \\
\hline Five-Factor Model (The baseline model) & 869.247 & 769 & 1.130 & 0.026 & 0.943 & 0.947 \\
\hline
\end{tabular}

Note: CFI = comparative fit index; TLI = Tucker-Lewis index; RMSEA = root mean square error of approximation; $\mathrm{AS}=$ Abusive supervision; EIB = employees' innovative behavior; CSE = creative self-efficacy; IMP = intrinsic motivational preference; EMP = extrinsic motivational preference.

Further, the results of the single factor test show that the variance of the first factor is $16.98 \%$, indicating an absence of common method bias [71].

\subsection{Descriptive Statistics and Correlation Analysis}

Table 2 presents the means, standard deviations, and zero-order Pearson correlations of all key variables. Abusive supervision was negatively correlated with EIB $(r=-0.41, p<0.01)$ and CSE $(r=-0.27, p<0.01)$. Moreover, CSE was positively correlated with $\operatorname{EIB}(r=0.37, p<0.01)$.

Table 2. Means, standard deviations, correlations, and alpha reliabilities for measures.

\begin{tabular}{lcccccccc}
\hline \multicolumn{1}{c}{ Variables } & Mean & SD & $\mathbf{1}$ & $\mathbf{2}$ & $\mathbf{3}$ & $\mathbf{4}$ & $\mathbf{5}$ & $\mathbf{6}$ \\
\hline 1. Gender & 1.52 & 0.50 & & & & & & \\
2. Education & 2.52 & 1.03 & $-0.16^{*}$ & & & & & \\
3. Position & 1.42 & 0.74 & $-0.26^{*}$ & $0.16^{*}$ & & & & \\
4. AS & 1.59 & 0.40 & -0.10 & 0.09 & $0.21^{* *}$ & & & \\
5. Motivational preference & -0.29 & 0.90 & -0.10 & -0.01 & 0.12 & $0.27^{* *}$ & & \\
6. CSE & 3.98 & 0.67 & -0.10 & 0.03 & -0.06 & $-0.27^{* *}$ & $-0.17^{* *}$ & \\
7. EIB & 4.07 & 0.53 & 0.02 & -0.02 & -0.08 & $-0.41^{* *}$ & $-0.31^{* *}$ & $0.37^{* *}$ \\
\hline
\end{tabular}

Note: ${ }^{*} p<0.05,{ }^{* *} p<0.01$ (two-tailed test); $\mathrm{SD}=$ standard deviations.

\subsection{Hypothesis Testing}

To test our hypotheses, a hierarchical multiple regression analysis (the linear least squares method) was conducted. As shown in Table 3, abusive supervision was negatively related to EIB $(\beta=-0.41$, $p<0.01$, Model 4). Therefore, Hypothesis 1 was supported. 
Table 3. Results of hierarchical regression analysis.

\begin{tabular}{|c|c|c|c|c|c|c|c|c|c|c|}
\hline \multirow{2}{*}{$\begin{array}{c}\text { Variables } \\
\text { Control variables }\end{array}$} & \multicolumn{5}{|c|}{ CSE } & \multicolumn{5}{|c|}{ Employees' Innovative Behavior } \\
\hline & M1 & M2 & M9 & M10 & M3 & M4 & M5 & M6 & M7 & M8 \\
\hline Gender & -0.12 & -0.13 & -0.13 & -0.12 & 0.02 & -0.01 & 0.05 & 0.02 & -0.03 & -0.002 \\
\hline Education & 0.02 & 0.04 & 0.04 & 0.03 & -0.01 & 0.02 & -0.01 & 0.01 & 0.01 & -0.002 \\
\hline Position & -0.10 & -0.04 & -0.03 & -0.001 & -0.08 & -0.002 & -0.05 & 0.01 & 0.01 & 0.06 \\
\hline \multicolumn{11}{|l|}{ Independent variable } \\
\hline AS & & $-0.28 * *$ & $-0.25 * *$ & $-0.19 * *$ & & $-0.41^{* *}$ & & $-0.33^{* *}$ & $-0.35^{* *}$ & $-0.22 * *$ \\
\hline \multicolumn{11}{|l|}{ Mediator } \\
\hline CSE & & & & & & & $0.37^{* *}$ & $0.28^{* *}$ & & \\
\hline Moderator & & & & & & & & & & \\
\hline Motivational preference & & & -0.10 & -0.05 & & & & & & -0.13 \\
\hline Interaction & & & & & & & & & & \\
\hline $\begin{array}{l}\text { AS * Motivational } \\
\text { preference }\end{array}$ & & & & $-0.19 *$ & & & & & & $-0.33^{* *}$ \\
\hline$F$ & 1.12 & $4.60^{* *}$ & $4.57^{* *}$ & $4.72 * *$ & 0.42 & $9.38 * *$ & $7.74^{* *}$ & $11.73^{* *}$ & $9.78^{* *}$ & $11.86^{* *}$ \\
\hline$\Delta F$ & 1.12 & $14.79 * *$ & 1.92 & 4.95 * & 0.42 & $36.03 * *$ & $29.51 * *$ & $17.74 * *$ & $10.25^{* *}$ & $17.79^{* *}$ \\
\hline$R^{2}$ & 0.02 & $0.09 * *$ & 0.11 & 0.13 * & 0.01 & $0.17^{* *}$ & $0.14^{* *}$ & $0.24^{* *}$ & $0.21^{* *}$ & $0.28^{* *}$ \\
\hline$\Delta R^{2}$ & 0.02 & $0.07^{* *}$ & 0.01 & 0.02 * & 0.01 & $0.16^{* *}$ & $0.14^{* *}$ & $0.07^{* *}$ & $0.04^{* *}$ & $0.07^{* *}$ \\
\hline
\end{tabular}

Note: ${ }^{*} p<0.05,{ }^{* *} p<0.01$.

Referring to Baron and Kenny's [73] procedures, we tested the mediating role of CSE in the relationship between abusive supervision and EIB with a series of hierarchical regression analyses. To examine the mediating effect $(X \rightarrow M \rightarrow Y$, i.e., Hypothesis 2$)$, three steps were needed: (1) abusive supervision (X) must affect EIB (Y); (2) abusive supervision $(X)$ must have an influence on employees' CSE (M); and (3) employees' CSE must affect innovative behavior (Y) when controlling for abusive supervision $(X)$, where the effect of abusive supervision $(X)$ on innovative behavior $(Y)$ is significantly reduced. The results showed that: (1) Abusive supervision was negatively related to CSE $(\beta=-0.28$, $p<0.01$, Model 2); (2) CSE was positively related to EIB ( $\beta=0.37, p<0.01$, Model 5), and (3) after adding CSE, compared to the negative effect of abusive supervision on EIB in Model 4 ( $\beta=-0.41$, $p<0.01$ ), the coefficient decreased $(\beta=-0.33, p<0.01$, Model 6$)$, while CSE continued to have a positive effect on EIB $(\beta=0.28, p<0.01$, Model 6$)$. Hence, Hypothesis 2 was partially supported. In addition, following Hayes [74], we determined the significance of the indirect effect by adopting the PROCESS program in SPSS 23.0. As a result, the indirect effect was found to be significant, as the $95 \%$ confidence interval excluded zero $(\beta=-0.10,[-0.238,-0.005])$. Since the bias-corrected confidence interval did not include zero, the indirect effect of abusive supervision on EIB via CSE is considered statistically significant. Thus, Hypothesis 2 was further supported.

To better understand the moderating effect, we followed the procedures of Aiken et al. [75] and calculated two types of the mean of motivational preference to plot the interaction. As shown in Figure 2, the interaction plot confirmed Hypothesis 3. More precisely, abusive supervision is more negatively related to innovative behavior when motivational preference is high (i.e., more IMP) $(\beta=-0.20, p<0.01)$ than when it is low (i.e., more EMP) $(\beta=-0.04$, n.s.). Hence, H3 is supported. Similarly, as shown in Figure 3, the interaction plot confirmed Hypothesis 4. More precisely, abusive supervision is more negatively related to CSE when motivational preference is high (i.e., more IMP) $(\beta=-0.19, p<0.01)$ than when it is low (i.e., more EMP) $(\beta=-0.07$, n.s.). Hence, H4 is supported.

To verify Hypothesis 3 and Hypothesis 4, a moderated regression analysis was employed to examine the moderating effects of motivational preference. As indicated by Table 3, the interaction between abusive supervision and motivational preference negatively influenced EIB $(\beta=-0.33$, $p<0.01$, Model 8); the interaction between abusive supervision and motivational preference negatively influenced CSE $(\beta=-0.19, p<0.05$, Model 10).

To verify the moderated mediation (Hypothesis 5), we employed bootstrapping. As shown in Table 4, the indirect impact of abusive supervision on EIB through CSE varied significantly across levels of motivational preference $(\Delta \beta=-0.07, p<0.01)$. Specifically, the indirect impact of abusive supervision on EIB through CSE was stronger when motivational preference was high $(\beta=-0.10$, $p<0.01)$ than when it was low $(\beta=-0.03$, n.s.). Therefore, Hypothesis 5 was supported. 


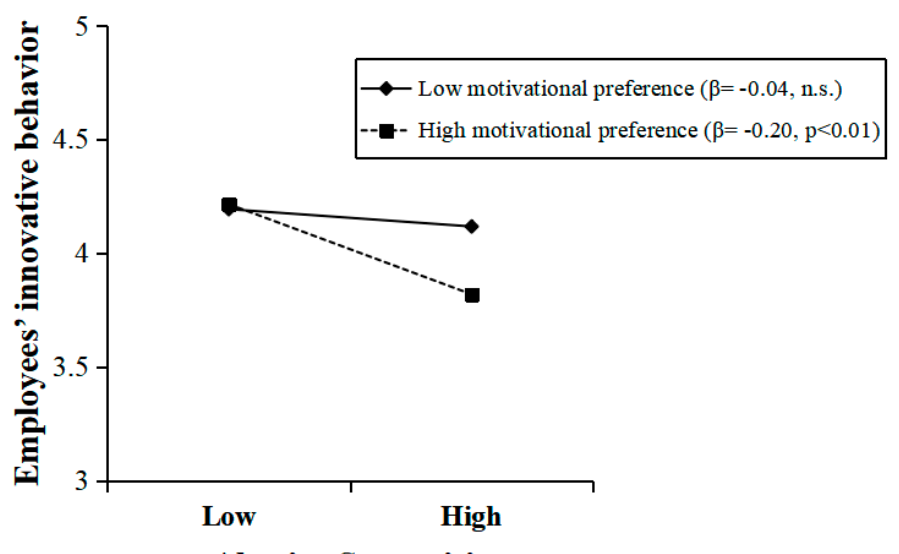

Figure 2. Moderating effect of motivational preference on the relationship between abusive supervision and EIB.

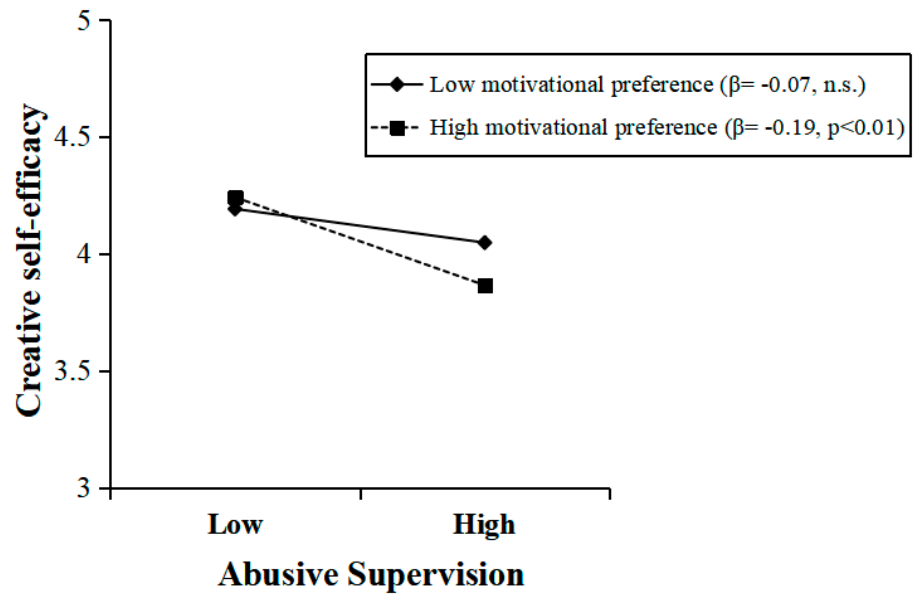

Figure 3. Moderating effect of motivational preference on the relationship between abusive supervision and creative self-efficacy.

Table 4. Results of the moderated path analysis.

\begin{tabular}{ccc}
\hline Moderator Variable & AS $\rightarrow$ CSE $\rightarrow$ EIB \\
\cline { 2 - 3 } & Estimate & 95\% Confidence Interval \\
\hline Simple paths for weak motivational preference & -0.03 & {$[-0.164,0.056]$} \\
Simple paths for strong motivational preference & $-0.10^{* *}$ & {$[-0.215,-0.015]$} \\
Differences & $-0.07^{* *}$ & {$[-0.146,-0.014]$} \\
\hline
\end{tabular}

Note: $N=190 ; * * p<0.01$. Weak motivational preference means one standard deviation below the mean value of motivational preference; strong motivational preference means one standard deviation above the mean value of motivational preference. Tests of differences for the indirect effect were based on bias-corrected confidence intervals obtained from bootstrapping estimates.

\section{Discussion}

This study analyzed whether abusive supervision could affect EIB and whether motivational preference could moderate this process. The findings demonstrate that abusive supervision significantly reduced EIB, and this effect was partially mediated by CSE. In addition, our findings indicate that the negative impact of abusive supervision on employees' CSE and innovative behavior can be influenced by employees' motivational preference. Employees with high motivational preference (i.e., more intrinsic motivational preference, IMP) are more vulnerable to abusive supervision and will have lower CSE and conduct less innovative behavior. Alternately, employees with low motivational preference (i.e., more extrinsic motivational preference, EMP) are less vulnerable to abusive supervision, 
and thus, the negative relationship is weaker between abusive supervision and their CSE, as well as innovative behavior.

Building sustainable organizations has gained a lot of attention. Our findings do have something crucially related to the long-term development of enterprises, as well as an individual's goal in the long run. For one thing, abusive supervision is a leadership style that is unsustainable. It has incalculable negative impacts on employees (including less passion for learning and creating), contributing to their mental and physical distress [76]. For another, EIB is beneficial to not only individuals, but also the organization. Without innovation, a company will have no core competitiveness, not to mention long-term benefits and expansion. It can be said that human behavior and subjective initiative determine the sustainable development of enterprises. Revealing the relationship between abusive supervision and EIB plays an important role in establishing sustainable enterprises, since the human factor is crucial in the process of establishing sustainability and cannot be ignored [76].

\subsection{Theoretical Implications}

What follows is a description of the theoretical contributions of this research. First, our study builds upon previous research into abusive supervision and EIB, taking the perspective of an integrated framework. While self-efficacy is a concept derived from SCT [48] and motivational preference is derived from self-determination theory (SDT), it is valuable to adopt both theories to integrate and interpret this framework. By exploring the mediating mechanism of employees' CSE and the moderating effects of motivational preference, our study supports the use of both theories in explaining the effects of abusive supervision on EIB.

Second, this study also demonstrates the mediating role of CSE, revealing the mechanism by which abusive supervision affects EIB. According to SCT [35], abusive supervision is an environment that negatively influences employees' cognition of their CSE. While CSE affects employees' behaviors, their innovative behavior decreases when CSE is reduced.

Third, we discovered the moderating role of employees' motivational preferences. A higher level of motivational preference corresponds to more IMP than EMP, while a lower level of motivational preference corresponds to more EMP than IMP. The literature surrounding abusive supervision has mainly focused on its negative outcomes, paying little attention to how employees' perceptions of abusive supervision may be affected [77,78]. We involved motivational preference in our framework and examined its moderating effect, which is an important boundary condition. Further, our study counters the claims made by Vansteenkiste et al. [79], who posit that focusing on inner desires (i.e., intrinsic motivation) increases happiness while focusing on outer desires (i.e., extrinsic motivation) leads to depression and anxiety. The results of this study suggest that EMP is not wholly negative, for when it outweighs IMP, corresponding to low motivational preference, the negative effects of abusive supervision may be reduced to some extent. Simultaneously, while intrinsic motivation can result in creativity [66], when it outweighs EMP, it will exacerbate the impact of abusive supervision on employees' CSE and innovative behavior. Our conclusions about motivational preference are illuminating.

Finally, a previous study showed that in the United States, more than $13 \%$ of the workforce has experienced abusive supervision or nonphysical hostility over a 12-month period [80]. However, great importance should also be attached to this issue in China. In response to the cultural differences between Western and Eastern countries, our study shows that even in the Chinese context, which advocates authority and power, abusive supervision is still an undesirable style of management, and it deserves more attention from researchers.

\subsection{Managerial Implications}

These results have several significant practical implications for enterprises. First, abusive supervision is found to negatively influence employees' innovative behavior; a result that suggests that enterprises should take measures to reduce the occurrence of abusive supervision. Managers should recognize that abusive supervision is detrimental to the long-term development of enterprises 
and take action to monitor supervisors' behavior. For example, conducting anonymous surveys about supervisors' management behavior among employees may be a way to avoid and expose abusive management. Furthermore, supervisors should be trained on effective management styles to ensure that they problem-solve constructively rather than in a hostile and aggressive way.

Second, some intervention measures should be adopted in response to abusive supervision. Organizations should not sit back and watch abusive supervision take place but should regulate supervisors' management behaviors. Enterprises should cultivate an excellent organizational culture and a favorable organizational atmosphere. In this way, supervisors and employees can maintain good relationships and abusive supervision can be avoided.

In addition, since CSE mediates the relationship between abusive supervision and employees' innovative behavior, it is necessary for organizations to have a deeper understanding of employees' CSE. The higher an employee's CSE is, the more likely they are to engage in innovative behavior. An organization's sustainable development is bettered by employing individuals with high CSE. Thus, organizations can cultivate employees' sense of CSE through training and team building in order to stimulate more employees' innovative behaviors.

Furthermore, our results reveal that employees with high motivational preference will conduct less innovative behavior when exposed to abusive supervision. This illustrates that employees with different motivational preferences will have different interpretations of workplace events, which will have different effects upon their innovative behavior. Therefore, to understand the motivational orientations and preference is of vital importance. Managers should provide different management styles and incentives for employees with different motivational preferences in order to combine them effectively into high-performing work teams [38].

\subsection{Limitations and Future Research Directions}

Despite the abovementioned contributions, our study still has several limitations. The first limitation is that the results may have been influenced by common method bias to some extent [71]. However, we took measures to minimize the effect of common method bias through the multi-wave and multi-source (i.e., from employees and supervisors) survey design, and the Harman's single factor test proved that the influence of common method bias in this study can be ignored [81]. Further, because abusive supervision is measured through employees' personal perceptions of their supervisors' management styles, we took a self-reporting approach. As abusive supervision is a sensitive topic, some employees may not have communicated their true feelings. Thus, future researchers may consider adopting alternative methods of measuring abusive supervision.

Second, our data was collected from three enterprises in Shenzhen, a city which is famous in China for its innovations in sustainable development. However, the high internal validity of this sample limits this study's external validity to some extent. In addition, as the data was collected in a Chinese context, it is affected by the influence of traditional Chinese culture, and different views of abusive supervision may be found in other contexts. Therefore, future researchers may conduct surveys in other regions and nations in order to verify the results of the present study.

Third, the scales adopted by this study were developed and adapted to a Western context. Due to the differences between Chinese and Western cultures, these measurements, especially those of abusive supervision, require further exploration. Their suitability, reliability, and validity in a Chinese context must be tested. Since the Chinese context has huge differences with other countries (e.g., Chinese culture emphasizes respect for authority, western culture values freedom), there are different organizational atmospheres and variable views on leadership styles. In the future, similar studies may be conducted in other cultural backgrounds to determine whether different implications exist.

Fourth, the present study examined the mediating role of CSE from the perspective of SCT. While the relationship between abusive supervision and innovative behavior is partially mediated by employees' CSE, other mediators might be found if different perspectives are taken. Future studies 
should aim to develop integrated frameworks to examine employees' innovative behavior from different theoretical perspectives.

Finally, we tested the moderating effect of individuals' relative tendencies between IMP and EMP on the relationship between abusive supervision and employees' creativity as well as innovative behavior. We calculated the score of MP by subtracting standardized EMP from IMP and examined its role as a moderator. Since IMP and EMP could coexist in an individual, it is worth receiving more attention from researchers to test their interactions; future research should test the three-way interactions (i.e., abusive supervision, IMP, and EMP at the same time).

Author Contributions: Conceptualization, J.T., Y.P. and X.Z.; Investigation, X.Z.; Methodology, J.T. and Y.P.; Resources, X.Z.; Supervision, X.Z.; Validation, J.T. and Y.P.; Writing-original draft, J.T. and Y.P.; Writing-review \& editing, J.T. and Y.P. All authors have read and agreed to the published version of the manuscript.

Funding: This research was funded by [Fundamental Research Funds for the Central Universities of Xiamen University] grant number [No. 20720201060].

Conflicts of Interest: The authors declare no conflict of interest.

\section{References}

1. Pieterse, A.N.; Van Knippenberg, D.; Schippers, M.; Stam, D. Transformational and Transactional Leadership and Innovative Behavior: The Moderating Role of Psychological Empowerment. J. Organ. Behav. 2010, 31, 609-623. [CrossRef]

2. Yuan, F.; Woodman, R.W. Innovative Behavior in the Workplace: The Role of Performance and Image Outcome Expectations. Acad. Manag. J. 2010, 53, 323-342. [CrossRef]

3. Anderson, N.; Potočnik, K.; Zhou, J. Innovation and Creativity in Organizations a State-of-the-Science Review, Prospective Commentary, and Guiding Framework. J. Manag. 2014, 40, 1297-1333.

4. Zhang, Y.; Zhang, J.; Forest, J.; Chen, C. The Negative and Positive Aspects of Employees' Innovative Behavior: Role of Goals of Employees and Supervisors. Front. Psychol. 2018, 9, 1871. [CrossRef]

5. Arasli, H.; Arici, H.E.; Kole, E. Constructive Leadership and Employee Innovative Behaviors: A Serial Mediation Model. Sustainability 2020, 12, 2592. [CrossRef]

6. Duradoni, M.; Di Fabio, A. Intrapreneurial Self-Capital and Sustainable Innovative Behavior within Organizations. Sustainability 2019, 11,322. [CrossRef]

7. Elidemir, S.N.; Ozturen, A.; Bayighomog, S.W. Innovative Behaviors, Employee Creativity, and Sustainable Competitive Advantage: A Moderated Mediation. Sustainability 2020, 12, 3295. [CrossRef]

8. Yu, X.; Paudel, K.P.; Li, D.; Xiong, X.; Gong, Y. Sustainable Collaborative Innovation between Research Institutions and Seed Enterprises in China. Sustainability 2020, 12, 624. [CrossRef]

9. Shalley, C.E.; Zhou, J.; Oldham, G.R. The Effects of Personal and Contextual Characteristics on Creativity: Where Should We Go from Here? J. Manag. 2004, 30, 933-958. [CrossRef]

10. Janssen, O. Innovative Behaviour and Job Involvement at the Price of Conflict and Less Satisfactory Relations with Co-Workers. J. Occup. Organ. Psychol. 2003, 76, 347-364. [CrossRef]

11. Janssen, O.; van de Vliert, E.; West, M.A. The Bright and Dark Sides of Individual and Group Innovation: A Special Issue Introduction. J. Organ. Behav. 2004, 25, 129-145. [CrossRef]

12. Shin, S.J.; Yuan, F.; Zhou, J. When Perceived Innovation Job Requirement Increases Employee Innovative Behavior: A Sensemaking Perspective. J. Organ. Behav. 2017, 38, 68-86. [CrossRef]

13. Tu, Y.D.; Lu, X.X. How Ethical Leadership Influence Employees' Innovative Work Behavior: A Perspective of Intrinsic Motivation. J. Bus. Ethics 2013, 116, 441-455. [CrossRef]

14. Opoku, M.A.; Choi, S.B.; Kang, S.W. Servant Leadership and Innovative Behaviour: An Empirical Analysis of Ghana's Manufacturing Sector. Sustainability 2019, 11, 6273. [CrossRef]

15. Yi, L.; Uddin, M.A.; Das, A.K.; Mahmood, M.; Sohel, S.M. Do Transformational Leaders Engage Employees in Sustainable Innovative Work Behaviour? Perspective from a Developing Country. Sustainability 2019, 11, 2485. [CrossRef]

16. Li, H.; Sajjad, N.; Wang, Q.; Muhammad Ali, A.; Khaqan, Z.; Amina, S. Influence of Transformational Leadership on Employees' Innovative Work Behavior in Sustainable Organizations: Test of Mediation and Moderation Processes. Sustainability 2019, 11, 1594. [CrossRef] 
17. Dedahanov, A.T.; Bozorov, F.; Sung, S. Paternalistic Leadership and Innovative Behavior: Psychological Empowerment as a Mediator. Sustainability 2019, 11, 1770. [CrossRef]

18. Dhar, R.L. Ethical Leadership and Its Impact on Service Innovative Behavior: The Role of LMX and Job Autonomy. Tour. Manag. 2016, 57, 139-148. [CrossRef]

19. Javed, B.; Abdullah, I.; Zaffar, M.A.; ul Haque, A.; Rubab, U. Inclusive Leadership and Innovative Work Behavior: The Role of Psychological Empowerment. J. Manag. Organ. 2019, 25, 554-571. [CrossRef]

20. Aquino, K.; Tripp, T.M.; Bies, R.J. Getting even or Moving on? Power, Procedural Justice, and Types of Offense as Predictors of Revenge, Forgiveness, Reconciliation, and Avoidance in Organizations. J. Appl. Psychol. 2006, 91, 653-668. [CrossRef]

21. Mahmood, F.; Qadeer, F.; Abbas, Z.; Muhammadi; Hussain, I.; Saleem, M.; Hussain, A.; Aman, J. Corporate Social Responsibility and Employees' Negative Behaviors Under Abusive Supervision: A Multilevel Insight. Sustainability 2020, 12, 2647. [CrossRef]

22. Tepper, B.J. Consequences of Abusive Supervision. Acad. Manag. J. 2000, 43, 178-190.

23. Frieder, R.E.; Hochwarter, W.A.; DeOrtentiis, P.S. Attenuating the Negative Effects of Abusive Supervision: The Role of Proactive Voice Behavior and Resource Management Ability. Leadersh. Q. 2015, 26, 821-837. [CrossRef]

24. Harris, K.J.; Kacmar, K.M.; Zivnuska, S. An Investigation of Abusive Supervision as a Predictor of Performance and the Meaning of Work as a Moderator of the Relationship. Leadersh. Q. 2007, 18, 252-263. [CrossRef]

25. Lyu, Y.; Zhu, H.; Zhong, H.J.; Hu, L. Abusive Supervision and Customer-Oriented Organizational Citizenship Behavior: The Roles of Hostile Attribution Bias and Work Engagement. Int. J. Hosp. Manag. 2016, 53, 69-80. [CrossRef]

26. Tepper, B.J.; Duffy, M.K.; Hoobler, J.; Ensley, M.D. Moderators of the Relationships between Coworkers' Organizational Citizenship Behavior and Fellow Employees' Attitudes. J. Appl. Psychol. 2004, 89, 455-465. [CrossRef]

27. Harvey, P.; Stoner, J.; Hochwarter, W.; Kacmar, C. Coping with Abusive Supervision: The Neutralizing Effects of Ingratiation and Positive Affect on Negative Employee Outcomes. Leadersh. Q. 2007, 18, 264-280. [CrossRef]

28. Tepper, B.J. Abusive Supervision in Work Organizations: Review, Synthesis, and Research Agenda. J. Manag. 2007, 33, 261-289. [CrossRef]

29. Aryee, S.; Chen, Z.X.; Sun, L.Y.; Debrah, Y.A. Antecedents and Outcomes of Abusive Supervision: Test of a Trickle-Down Model. J. Appl. Psychol. 2007, 92, 191-201. [CrossRef]

30. Martinko, M.J.; Harvey, P.; Brees, J.R.; Mackey, J. A Review of Abusive Supervision Research. J. Organ. Behav. 2013, 34, S120-S137. [CrossRef]

31. Rousseau, V.; Aube, C. When Leaders Stifle Innovation in Work Teams: The Role of Abusive Supervision. J. Bus. Ethics 2018, 151, 651-664. [CrossRef]

32. Zhu, J.; Zhang, B. The Double-Edged Sword Effect of Abusive Supervision on Subordinates' Innovative Behavior. Front. Psychol. 2019, 10, 66. [CrossRef] [PubMed]

33. Wang, D.; Li, X.; Zhou, M.; Maguire, P.; Zong, Z.; Hu, Y. Effects of Abusive Supervision on Employees' Innovative Behavior: The Role of Job Insecurity and Locus of Control. Scand. J. Psychol. 2019, 60, 152-159. [CrossRef] [PubMed]

34. Deci, E.L.; Ryan, R.M. The "What" and "Why" of Goal Pursuits: Human Needs and the Self-Determination of Behavior. Psychol. Inq. 2000, 11, 227-268. [CrossRef]

35. Bandura, A. Social Foundations of Thought and Action: A Social Cognitive Theory; Prentice-Hall: Englewood Cliffs, NJ, USA, 1986.

36. Bandura, A. Self-Efficacy: The Exercise of Control; Freeman: New York, NY, USA, 1997.

37. Bandura, A. Social Cognitive Theory: An Agentic Perspective. Annu. Rev. Psychol. 2001, 52, 1-26. [CrossRef]

38. Amabile, T.M. Motivational synergy: Toward new conceptualizations of intrinsic and extrinsic motivation in the workplace. Hum. Resour. Manag. Rev. 1993, 3, 185-201. [CrossRef]

39. Amabile, T.M.; Hill, K.G.; Hennessey, B.A.; Tighe, E.M. The Work Preference Inventory: Assessing Intrinsic and Extrinsic Motivational Orientations. J. Personal. Soc. Psychol. 1994, 66, 950-967. [CrossRef]

40. Tepper, B.J.; Duffy, M.K.; Shaw, J.D. Personality Moderators of the Relationship between Abusive Supervision and Subordinates' Resistance. J. Appl. Psychol. 2001, 86, 974-983. [CrossRef] 
41. Lee, S.; Yun, S.; Srivastava, A. Evidence for a Curvilinear Relationship between Abusive Supervision and Creativity in South Korea. Leadersh. Q. 2013, 24, 724-731. [CrossRef]

42. Rafferty, A.E.; Restubog, S.L.D. The Influence of Abusive Supervisors on Followers' Organizational Citizenship Behaviours: The Hidden Costs of Abusive Supervision. Br. J. Manag. 2011, 22, 270-285. [CrossRef]

43. Liao, H.; Liu, D.; Loi, R. Looking at Both Sides of the Social Exchange Coin: A Social Cognitive Perspective on the Joint Effects of Relationship Quality and Differentiation on Creativity. Acad. Manag. J. 2010, 53, 1090-1109. [CrossRef]

44. Liu, D.; Jiang, K.; Shalley, C.E.; Keem, S.; Zhou, J. Motivational Mechanisms of Employee Creativity: A Meta-Analytic Examination and Theoretical Extension of the Creativity Literature. Organ. Behav. Hum. Decis. Process. 2016, 137, 236-263. [CrossRef]

45. Scott, S.G.; Bruce, R.A. Determinants of Innovative Behavior: A Path Model of Individual Innovation in the Workplace. Acad. Manag. J. 1994, 37, 580-607.

46. Amabile, T.M. The Social Psychology of Creativity: A Componential Conceptualization. J. Personal. Soc. Psychol. 1983, 45, 357-376. [CrossRef]

47. Schunk, D.H.; Usher, E.L. Social cognitive theory and motivation. In The Oxford Handbook of Human Motivation, 2nd ed.; Ryan, R.M., Ed.; Oxford University Press: New York, NY, USA, 2019.

48. Schunk, D.H.; Dibenedetto, M.K. Motivation and Social Cognitive Theory. Contemp. Educ. Psychol. 2020, 60, 101832. [CrossRef]

49. Deci, E.L.; Ryan, R.M. Facilitating Optimal Motivation and Psychological Well-Being across Life's Domains. Can. Psychol. 2008, 49, 14-23. [CrossRef]

50. Tierney, P.; Farmer, S.M. Creative Self-Efficacy: Its Potential Antecedents and Relationship to Creative Performance. Acad. Manag. J. 2002, 45, 1137-1148.

51. Tierney, P.; Farmer, S.M. Creative Self-Efficacy Development and Creative Performance over Time. J. Appl. Psychol. 2011, 96, 277-293. [CrossRef]

52. Hon, A.H.Y.; Chan, W.W.H. Team Creative Performance: The Roles of Empowering Leadership, Creative-Related Motivation, and Task Interdependence. Cornell Hosp. Q. 2013, 54, 199-210. [CrossRef]

53. Zhou, J.; Hoever, I.J. Research on Workplace Creativity: A Review and Redirection. Annu. Rev. Organ. Psychol. Organ. Behav. 2014, 1, 333-359. [CrossRef]

54. Bandura, A. Social Cognitive Theory in Cultural Context. Appl. Psychol. 2002, 51, 269-290. [CrossRef]

55. Kim, H.; Chen, Y.; Kong, H. Abusive Supervision and Organizational Citizenship Behavior: The Mediating Role of Networking Behavior. Sustainability 2020, 12, 288. [CrossRef]

56. Bandura, A.; Locke, E.A. Negative Self-Efficacy and Goal Effects Revisited. J. Appl. Psychol. 2003, 88, 87-99. [CrossRef] [PubMed]

57. Slåtten, T. Determinants and Effects of Employee's Creative Self-Efficacy on Innovative Activities. Int. J. Qual. Serv. Sci. 2014, 6, 326-347. [CrossRef]

58. Peng, Y.P. A Study of the Relationship among Leader-Member Exchange, Creative Self-Efficacy and Innovative Behavior of the University Librarians. J. Educ. Media Libr. Sci. 2016, 53, $27-61$.

59. Bandura, A.; Cervone, D. Self-Evaluative and Self-Efficacy Mechanisms Governing the Motivational Effects of Goal Systems. J. Personal. Soc. Psychol. 1983, 45, 1017-1028. [CrossRef]

60. Gong, Y.; Huang, J.C.; Farh, J.L. Employee Learning Orientation, Transformational Leadership, and Employee Creativity: The Mediating Role of Employee Creative Self-Efficacy. Acad. Manag. J. 2009, 52, 765-778. [CrossRef]

61. Wang, C.J.; Tsai, H.-T.; Tsai, M.T. Linking Transformational Leadership and Employee Creativity in the Hospitality Industry: The Influences of Creative Role Identity, Creative Self-Efficacy, and Job Complexity. Tour. Manag. 2014, 40, 79-89. [CrossRef]

62. Michael, L.A.H.; Hou, S.-T.; Fan, H.-L. Creative Self-Efficacy and Innovative Behavior in a Service Setting: Optimism as a Moderator. J. Creat. Behav. 2011, 45, 258-272. [CrossRef]

63. Zhou, Q.; Li, Q.; Gong, S. How Job Autonomy Promotes Employee's Sustainable Development? A Moderated Mediation Model. Sustainability 2019, 11, 6445. [CrossRef]

64. Hitka, M.; Lorincová, S.; Ližbetinová, L.; Schmidtová, J. Motivation Preferences of Hungarian and Slovak Employees Are Significantly Different. Period. Polytech. Soc. Manag. Sci. 2017, 25, 117-126. [CrossRef]

65. Gagné, M.; Deci, E.L. Self-Determination Theory and Work Motivation. J. Organ. Behav. 2005, 26, 331-362. [CrossRef] 
66. Ryan, R.M.; Deci, E.L. Intrinsic and Extrinsic Motivations: Classic Definitions and New Directions. Contemp. Educ. Psychol. 2000, 25, 54-67. [CrossRef] [PubMed]

67. Miao, S.; Rhee, J.; Jun, I. How Much Does Extrinsic Motivation or Intrinsic Motivation Affect Job Engagement or Turnover Intention? A Comparison Study in China. Sustainability 2020, 12, 3630. [CrossRef]

68. Silva, W.F.; Redondo, R.P.; Cardenas, M.J. Intrinsic Motivation and Its Association with Cognitive, Actitudinal and Previous Knowledge Processes in Engineering Students. Contemp. Eng. Sci. 2018, 11, 129-138. [CrossRef]

69. Chatard, A.; Selimbegović, L. When Self-Destructive Thoughts Flash Through the Mind: Failure to Meet Standards Affects the Accessibility of Suicide-Related Thoughts. J. Personal. Soc. Psychol. 2011, 100, 587-605. [CrossRef] [PubMed]

70. Ryan, R.M.; Deci, E.L. An overview of Self-Determination Theory: An organismic-dialectical perspective. In Handbook of Self-Determination Research; Deci, E.L., Ryan, R.M., Eds.; The University of Rochester Press: Rochester, NY, USA, 2002; pp. 3-33.

71. Podsakoff, P.M.; Mackenzie, S.B.; Lee, J.-Y.; Podsakoff, N.P. Common Method Biases in Behavioral Research: A Critical Review of the Literature and Recommended Remedies. J. Appl. Psychol. 2003, 88, 879-903. [CrossRef]

72. Brislin, R.W. Expanding the Role of the Interpreter to Include Multiple Facets of Intercultural Communication. Int. J. Intercult. Relat. 1980, 4, 137-148. [CrossRef]

73. Baron, R.M.; Kenny, D.A. The Moderator-Mediator Variable Distinction in Social Psychological Research: Conceptual, Strategic, and Statistical Considerations. J. Personal. Soc. Psychol. 1986, 51, 1173-1182. [CrossRef]

74. Hayes, A.F. Introduction to Mediation, Moderation, and Conditional Process Analysis; The Guilford Press: New York, NY, USA, 2017.

75. Aiken, L.S.; West, S.G.; Reno, R.R. Multiple Regression: Testing and Interpreting Interactions; SAGE: Newbury Park, CA, USA, 1991.

76. Pfeffer, J. Building Sustainable Organizations: The Human Factor. Acad. Manag. Perspect. 2010, $24,34-45$.

77. Mackey, J.D.; Frieder, R.E.; Brees, J.R.; Martinko, M.J. Abusive Supervision: A Meta-Analysis and Empirical Review. J. Manag. 2017, 43, 1940-1965. [CrossRef]

78. Zhang, Y.; Liao, Z. Consequences of Abusive Supervision: A Meta-Analytic Review. Asia Pac. J. Manag. 2015, 32, 959-987. [CrossRef]

79. Vansteenkiste, M.; Simons, J.; Lens, W.; Sheldon, K.M.; Deci, E.L. Motivating Learning, Performance, and Persistence: The Synergistic Effects of Intrinsic Goal Contents and Autonomy-Supportive Contexts. J. Personal. Soc. Psychol. 2004, 87, 246-260. [CrossRef] [PubMed]

80. Tepper, B.J.; Moss, S.E.; Duffy, M.K. Predictors of Abusive Supervision: Supervisor Perceptions of Deep-Level Dissimilarity, Relationship Conflict, and Subordinate Performance. Acad. Manag. J. 2011, 54, 279-294. [CrossRef]

81. Cheng, B.; Zhou, X.; Guo, G.; Yang, K. Perceived Overqualification and Cyberloafing: A Moderated-Mediation Model Based on Equity Theory. J. Bus. Ethics 2020, 164, 565-577. [CrossRef]

Publisher's Note: MDPI stays neutral with regard to jurisdictional claims in published maps and institutional affiliations.

(C) 2020 by the authors. Licensee MDPI, Basel, Switzerland. This article is an open access article distributed under the terms and conditions of the Creative Commons Attribution (CC BY) license (http://creativecommons.org/licenses/by/4.0/). 